\title{
Self-Concept among Adolescents of Mixed Sex and Single Sex Education Schools
}

\author{
Shreshtha Dhar ${ }^{1 *}$, Saranya Banerjee ${ }^{1}$, Anindita Mukherjee ${ }^{1}$, Atanu Kumar Dogra ${ }^{2}$
}

\section{ABSTRACT}

School plays a vital role in biopsychosocial development among students. One of the common debates of modern educational system is whether mixed sex education or single-sex education is beneficial for the bio psychosocial development of adolescents. However previous research findings have not provided sufficient evidence to resolve the controversies, this study aimed at clarifying the question of 'which nature of schooling is effective for multi-dimensional self concept?' To resolve the controversy, self concept of boys and girls of four mixed sex schools and four single sex education schools was assessed with the help of Multidimensional selfconcept scale (MSCS)(Bruce and Bracken, 1992) . Data were statistically analyzed with help of $t$ test. As per result, competence and academic dimensions of self were found to be higher in students from single sex schooling but social dimension of self was elevated in students from mixed sex schooling for both sexes. Girls were found to have scored significantly higher than boys on social dimension of self for both types of schooling.

Keywords: Self-Concept, Mixed Sex And Single Sex School.

Schooling is an essential part of everyone's life. Besides family, school also helps people to know how to move in society, how to behave with others and how to progress in life. Especially, it is an essential place where children have interactions with their peers, form companionship, and participate in social groups with other children. Especially, as children grow up from infancy to adolescence, peers and school gradually become more significant in their lives. But a question arises in parents that which type of schooling (same sex verses mixed sex) is beneficial for their child. Some parents feel and prefer traditional unisex education due to sex disparities in psychosocial development, but others think that unisex schooling is not an effective process for the development of an androgynous personality of the individual. So, they prefer the trend of mixed sex education.

\footnotetext{
${ }^{1}$ Research Students, Department of Psychology, University of Calcutta

${ }^{2}$ Assistant Professor, Department of Psychology, University of Calcutta

*Responding Author

(C) 2016 I S Dhar, S Banerjee, A Mukherjee, A Dogra; licensee IJIP. This is an Open Access Research distributed under the terms of the Creative Commons Attribution License (http://creativecommons.org/licenses/by/2.0), which permits unrestricted use, distribution, and reproduction in any Medium, provided the original work is properly cited.
} 


\section{Self-Concept among Adolescents of Mixed Sex and Single Sex Education Schools}

So, social scientists always face a controversy about the effectiveness of mixed sex education and unisex education on bio-psychosocial development of children. In their developmental process, one of the important issues is self development. Self-concept is used to refer to how someone thinks about, evaluates or perceives themselves. According to Bracken (1992, p.10),self-concept is 'a multidimensional and context-dependent learned behavioural pattern that reflects an individual's evaluation of past behaviours and experiences, influences an individual's current behaviours, and predicts an individual's future behaviours. 'These different dimensions are unique and distinct. During the span of development, these different dimensions of self concept of every individual develop in different directions according to their exposure. From student's perspective, although some studies found that self-concept for girls were more obtained in female-only environments (e.g., Cipriani-Sklar, 1996; Riordan, 1990), girls also get greater self-confidence in cognitive domains in single-sex classes (Cairns, 1990) and mathematics (Mallam, 1993) and persistence in mathematics (Rowe, 1988), but Wing-man Winnie (1994) found that mixed sex education is better than single-sex education for the psychosocial development of adolescents, because single-sex schools segregate its students from peers of the opposite sex.

Hence, over the past five decades of researches, there has been ongoing debate about the advantages of mixed sex educational and single-sex education for children's bio-psycho-social and educational development; there is no conclusive finding from previous studies to resolve the controversy. So the objectives of the research are: a)to compare between different dimensions of Self-concept of the students studying in a mixed sex education school and single sex education school separately. b) to compare between different dimensions of Self-concept of the boys and girls studying in a mixed sex education school and Single sex education school separately.

\section{METHOD:}

\section{Participant:}

The total numbers of participants in the study were six hundred students studying in the secondary schools in Kolkata. From those entire participants, 150 females \& 150 males were purposively selected from four mixed sex education schools and 150 females and150 males were purposively selected from four single sex education school son the basis of following inclusion criteria were:1) Age of the subjects: Between 13 to 15 years. 2) Locality: Residing in Kolkata for at least 5 years.3) Religion: Adolescents belonging to Hinduism were included in the sample.4) Educational Status: Students of 9th and 10th standard.5) Educational institution: Students of recognized private single sex and mixed sex education English medium schools from standard one.6) Parental Income: Rs 40,000 to Rs 50,000 per capita7) No. of Sibling: None. 8) None of the students were transfer students. 9) All the participants attended mixed sex coaching centres for 4-6 hours every week. 


\section{Self-Concept among Adolescents of Mixed Sex and Single Sex Education Schools}

The exclusion criteria were:

1) History of any acute physical illness, physical handicaps or chronic illness having residual effect. 2) History of any past psychiatric illness.3) Any present illness or history of any mental illness, having residual effect. 4) Students not willing to answer all the items of the questionnaires. 5) Students having access to social networking sites.

\section{Instrument:}

The data for this study was collected from the following sources:

a) Personal information schedule includes socio-demographical details and psychological profiles.

b) Multidimensional self-concept scale (Bruce and Bracken, 1992):The MSCS is based on a hierarchical model of self concept. This model presumes that the multiple dimensions that constitute self concept are moderately intercorrelated. This includes include social, competence, affect, physical, academic and family (e.g., Bannister \& Agnew, 1977).Bracken (1992) reported high internal reliability estimates, ranging from .87 on the Competence subscale to .98 on the Total scale. Concurrent validity results have shown full scale correlations between the MSCS and the Coppersmith Self-Esteem Inventory, the Piers-Harris Children's Self-Concept Scale and the Self Description Questionnaire II ranging from .69 to .83.

\section{Procedure of study:}

The selected schools were visited and the Principals or Vice Principals of the respective schools were approached for their approval and cooperation to collect data from their students. The subjects were selected on the basis of the inclusion/exclusion criteria after getting their consent. After obtaining permission and ensured cooperation, the students were approached. The nature of the research was explained to them. They were asked to volunteer for the study and it was assured that their responses will be strictly confidential and it would not be used in any other way apart from using it in the present study. They were asked to fill up the Personal Information Schedule. Then MSCS was given to the students and asked to fill them up. Clear instructions were given before administration of each questionnaire and its response categories. Ambiguities arising during and after administration of the questionnaires were clarified by the researcher.

\section{Examination, Scoring and Treatment of Data:}

The statistical treatments of the scores were done by using SPSS version 21.0. Keeping in view the objectives as well as design of the study, mean, standard deviation and inferential statistics were done to calculate all data. Since homogeneity of error variances exist among group (measured in terms of levene test), independent $t$ tests were done to measure significant difference between means. 


\section{Self-Concept among Adolescents of Mixed Sex and Single Sex Education Schools}

\section{RESULTS:}

In comparison between single sex and coeducation, significant differences were observed in competence $[\mathrm{t}(\mathrm{df}=298)=9.85(\mathrm{p}<.01)$ for boys and $\mathrm{t}(\mathrm{df}=298)=10.69(\mathrm{p}<.01)$ for girls] and academic dimensions $[\mathrm{t}(\mathrm{df}=298)=12.95(\mathrm{p}<.01)$ for boys and $\mathrm{t}(\mathrm{df}=298)=10.60(\mathrm{p}<.01)$ for girls] among all dimensions of self concept and it was also found that higher scores are observed in students from single sex schooling than mixed sex schooling. In other side, social dimension of self $[\mathrm{t}(\mathrm{df}=298)=6.57(\mathrm{p}<.01)$ for boys and $\mathrm{t}(\mathrm{df}=298)=8.18(\mathrm{p}<.01)]$ was elevated in students from mixed sex schooling for both sexes than students from single sex schooling. In comparison between boys and girls, Girls were found to have scored significantly higher than boys on the social dimension of self-concept for both types of schooling $[\mathrm{t}(\mathrm{df}=298)$ $=13.07(\mathrm{p}<.01)$ for coeducation and $\mathrm{t}(\mathrm{df}=298)=10.30(\mathrm{p}<.01)$ for single sex school].

\section{DISCUSSION:}

Self concept is a social cognitive multidimensional construct (Bergman, 2004; Harter, 2006) and among different socio-cultural mirrors like family, schooling, peer group, school plays as a chief determinant in development of self. Especially, though, adolescent spends more time in school than any other place outside of their home, interaction with peers, teachers, curriculum and cocurriculum influence their self development. In the present study, role of nature of schooling on social, academic and competent dimensions of self concept were observed.

Social self concept is conceptualized as the self-evaluation which is derived from their social interactions with significant others. It depends upon their conformity to the expectation of their peer groups, their role playing and how they are judged by others. As a whole, the environment and its feedback have a role in the development of the social self concept. In comparison between two types of schooling, adequate Social self concept is more developed in children of mixed sex schooling than in single sex schooling. Since students from both the types of schools were exposed to mixed sex coaching centers for 4-6 hours every week, it might be inferred that the difference in the social self concept of the students is due to the differences in the nature of the schooling. The difference might have occurred because students from the mixed sex schools get more opportunity to interact with peer groups irrespective of their sexes. It facilitates to learn how to play different roles and reach the expectation of the social group. It might enhance their communication skills, experiences and knowledge of gender equality which is helpful for perspective taking of opposite sex. Hence, these traits might be generalized in their flexible, friendly attitude toward opposite sex in real social life and it is also reciprocated from society also. It helps to develop better social self concept. So, their social self was better than students from single sex schooling. Findings of few British literatures (Dale, 1969, 1971, 1974; Schmuck, 2005; Smyth, 2010) are consistent with the present study that co-educational schooling was healthier for development of both sexes.

In case of competence and academic domains of self, the picture is opposite. Competence self refers to the self evaluation toward one's abilities and academic self is conceptualized as self 


\section{Self-Concept among Adolescents of Mixed Sex and Single Sex Education Schools}

appraisal regarding own academic success. Although own abilities play a role, children have a tendency to evaluate own self based on the performance of others and how others (friends and teachers) evaluate them on their academic performance. Similarly, competence or ability self depends upon perception towards own capability and limitation of a child. Students from single sex schooling express their self competence and academic self better than students of mixed sex school. This difference might be occurred due to a few reasons:

Firstly, it might have occurred due to the notion of gender stereotypes regarding the capabilities of specific few subjects 'understanding. So, in case of mixed schooling, when they are forced to express their performance in gender atypical subjects, they lose their confidence which is reflected in their self concept and self efficacy. A substantial amount of literatures (Halpern et al,2007; Mael,1998;Marsh \&Yeung,1998) suggest that boys have higher academic self concepts in 'masculine' subject areas based on visuospatial skills but girls may be expected to have higher verbal abilities than boys.

On another side, in the single sex learning environment, the effects of gender stereotypes have been shown to be lesser and students of both sexes are more likely to take subjects and participants in activities outside traditional sex roles (Billger, 2009; Dalley-Trim,2007). Studies by Cater,2005;Malacova,2007; Eisenkopf et al.,2012 have found that females frequently expressed more confidence and achieved better in the single sex schooling environment.

Secondly, it might have occurred because boys contribute more to classroom interaction in mixed sex schooling (Francis, 2004) and boys tend to be more disruptive in classroom interaction (Francis 2000) which adversely affect girls academic engagement and achievement and finally, on self .

From the perspective of sex, social dimension of self is significantly higher in girls rather than boys irrespective of schooling. It might be because of our cultural learning. In our society, girls are more forced to learn social rules, moral values from adolescence than boys. These are reflected through healthier social interaction and constitute the social self concept. This findings are consistent with Rosenberg and Simmons (2000) also stated that girls in adolescence are more conscious and more concerned with promoting interpersonal harmony.

\section{CONCLUSION:}

Overall, the present study reveals a controversial picture about the efficacy of schooling on development of self concept among adolescent. Hence competence and academic dimensions of self was found to be higher in students from single sex schooling and social dimension of self was elevated in students from mixed sex schooling for both sexes. Therefore one can attempt to set up a school where students of both sexes are free to interact with each other in their leisure time but they are given the opportunity to acquire the knowledge in separate classrooms. This setup might be more effective than present schooling style in Bengali culture. 


\section{REFERENCES}

Bannister, D., and Agnew, J. (1977). The child's construing of self. Nebraska symposium on motivation, 1976, edited by J.Cole. Lincoln: University of Nebraska Press. 99-125.

Bergman, R. (2004). Identity as Motivation: Toward a theory of Moral self. In D. Lapsley, \& D. (. Narvez, moral development, self-identity. Mahwah, NewJersey: Erlbaum.

Billger, S. M. (2009). On reconstructing school segregation: The efficacy and equity of singlesex schooling. Economics of Education Review 28:393-402

Bracken, B. A. (1992). Multidimensional Self-Concept Scale. Austin, TX: Pro-Ed.

Cairns, E. (1990). The relationship between adolescent perceived self-competence and attendance at single-sex secondary school. British Journal of Educational Psychology 60:207-211.

Cater, T. (2005). The effects of single sex schooling on girls' achievement in physical science (Unpublished Master of Education thesis). University of South Africa

Cipriani-Sklar, R. (1996). A quantitative and qualitative examination of the influence of the normative and perceived school environments of a coeducational public school vs. a single-sex Catholic school on ninth-grade girls' science self-concept and anxiety in the area of science education. Dissertation Abstracts International, 57(10), 4312A.

Dale, R.R. (1969). Mixed or single-sex school? Vol. 1. A research study about pupil-teacher relationships. London: Routledge \& Kegan Paul.

Dale, R.R. (1971). Mixed or single-sex school? Vol. 2. Some social aspects. London: Routledge \& Kegan Paul.

Dale, R.R. (1974). Mixed or single-sex school? Vol. 3. Attainment attitude and overview. London: Routledge \& Kegan Paul.

Dalley-Trim, Leanne (2007) 'The boys' present... hegemonic masculinity: a performance of multiple acts. Gender and Education, 19 (2). pp. 199-217.

Eisenkopf, G., Hessami Z.,Fischbacher, U., \&Ursprung, H. (2012). Academic performance and single-sex schooling: Evidence from a natural experiment in Switzerland, University of Konstanz Working Paper.

Francis, B. (2004). Classroom interaction and access: Whose space is it? In H. Claire(Ed) Gender in education: A fresh approach (3-19), London: Association of Teachers and Lecturers.

Francis, B. 2000. Boys, Girls and Achievement. London: Routledge Falmer.

Halpern, D.F. (2007) The Science of Sex Differences in Science and Mathematics. Psychological Science in the Public Interest August 2007 vol. 8 no. 1: 1-51

Harter, S. (2006). The development of Self-representations on childhood and adolescence. In W. damon, \& R. (Lerner, handboo kof child psychology 6th ed. New York: Wiley.

Mael, F. A. (1998). Single-Sex and Coeducational Schooling: Relationships to Socioemotional and Academic Development. Review of Educational Research 68(2).

Malacova , E. (2007). Effect of single-sex education on progress in GCSE. Oxford Review of Education 33:233-259 
Mallam, W. (1993). Impact of school-type and sex of the teacher on female students' attitudes toward mathematics in Nigerian secondary schools. Educational Studies in Mathematics, 24, 223-229.

Marsh, H.W. and Yeung, A.S. (1998). Longitudinal structural equation models of academic self concept and achievement: Gender differences in the development of math and English constructs. American Education Research Journal. 35(4), 705-738.

Riordan, C. (1985). Public and Catholic schooling: The effects of gender context policy. American Journal of Education, 93, 518-540.

Rosenberg, F.R., Simmons, R.G. (1975). Sex differences in the self-concept in adolescence. Sex Roles. 1(2), pp 147-159.

Rowe, K.J. (1988). Single-sex and mixed sex classes: The effects of class type on student achievement. Australian Journal of Education, 32, 180-202.

Schmuck. P.(2005). Same, different, equal: Rethinking single-sex schooling. American Journal of Education, Vol. 111, No. 2, p.271.

Smyth, E. (2010), “Single-Sex Education: What does Research tell us?” Revue Française de Pédagogie, vol. 171, pp. 47-55.

Wing-man Winnie, L. (1994). A Study on the Self-concept and Sex-Role Orientation of Students of Single-Sex and Co-educational Secondary Schools. Published article.

Table 1: Showing Means And Standard Deviations For Self-Concept For Single Sex Education School And Co- Education School Children.

\begin{tabular}{|c|c|c|c|c|c|c|c|c|}
\hline \multirow{3}{*}{$\begin{array}{l}\text { Self } \\
\text { concept }\end{array}$} & \multicolumn{4}{|c|}{ Male } & \multicolumn{4}{|c|}{ Female } \\
\hline & \multicolumn{4}{|c|}{ Co- education Single sex education } & \multicolumn{2}{|c|}{ Co- education } & \multicolumn{2}{|c|}{ Single sex education } \\
\hline & Mean & SD & an & $\mathrm{D}$ & Mean & SD & Mean & \\
\hline Social & 71.8 & 6.93 & 66.8 & 6.27 & 82.78 & 7.63 & 75.66 & 8.06 \\
\hline Competence & 64.74 & 6.77 & 72.62 & 7.29 & 63.36 & 7.28 & 72.34 & 7.57 \\
\hline Affect & 74.26 & 7.21 & 72.7 & 7.83 & 73.58 & 8.09 & 75.14 & 14.48 \\
\hline Academic & 62.86 & 8.13 & 73.74 & 6.39 & 64.96 & 11.05 & 75.64 & 8.49 \\
\hline Family & 75.76 & 10.04 & 78.08 & 10.99 & 77.12 & 9.20 & 76.4 & 8.56 \\
\hline Physical & 75.74 & 10.15 & 73.41 & 8.75 & 73.78 & 9.37 & 71.6 & 10.56 \\
\hline
\end{tabular}


Table 2 : Showing $t$ values between different dimensions of self concept of boys and girls of both types of schools and t values between different dimensions of self concept of single sex and coeducation students of boys and girls separately.

\begin{tabular}{|l|lc|lc|}
\hline Self concept & $\begin{array}{l}\text { Between co -education \& single } \\
\text { sex education for boys \&girls }\end{array}$ & $\begin{array}{l}\text { Between boys \&girls for } \\
\text { co-education single sex education }\end{array}$ \\
\hline Social & $6.57^{* *}$ & $8.18^{* *}$ & $13.07^{* *}$ & $10.30^{* *}$ \\
Competence & $9.85^{* *}$ & $10.69^{* *}$ & 1.725 & 0.32 \\
Affect & 1.75 & 0.75 & 0.92 & 1.67 \\
Academic & $12.95^{* *}$ & $10.60^{* *}$ & 1.36 & 1.66 \\
Family & 1.88 & 1.68 & 1.13 & 1.83 \\
Physical & 1.63 & 1.59 & 1.73 \\
\hline
\end{tabular}

